\title{
Electron Transfer to Decorated Graphene Oxide Particles
}

\author{
Ruiyang Miao, ${ }^{[\mathrm{a}]}$ Lifu Chen, ${ }^{[\mathrm{a}]}$ Lidong Shao ${ }^{[\mathrm{b}]}$ Bingsen Zhang, ${ }^{[\mathrm{c}]}$ and Richard G. Compton ${ }^{\star[a]}$
}

\begin{abstract}
Graphene oxides (GOs) are popular catalyst supports for precious metals in nanoparticle form. The hydrogen oxidation reaction (HOR) and the hydrogen evolution reaction (HER) on individual GO platelets decorated with $\mathrm{Pd}$ nanoparticles (Pd/GOs) were investigated and suggest that the catalytic activity is confined to zone physically close to the point of electrical contact between platelet and electrode with just a fraction of the platelet active.
\end{abstract}

Graphene oxide (GO) is a widely-used support for nanoparticle catalysis (details in SI Section 1) ${ }^{[1]}$ In the context of redox and electro catalysis, the rate of heterogeneous electron transfer (HET) to and from the decorated GO particles is a key parameter characterizing their catalytic role. Eng et al. reported that for $\left[\mathrm{Fe}(\mathrm{CN})_{6}\right]^{3-14-}$ in aqueous solution, the electron transfer rate constant on GO was slow but increased significantly on potassium-doped GO, giving a value comparable with that of graphene. ${ }^{[2]}$ Punckt et al. investigated the effect of the reduction degree of $\mathrm{GO}$ upon the HET rate for the $\left[\mathrm{Fe}(\mathrm{CN})_{6}\right]^{4-/ 3-}$ couple in aqueous solution via electrochemical impedance spectroscopy. ${ }^{[3]}$ However, the accurate assessment of the rate of HET is challenging if, as is usual, it is measured from an ensemble of particles, since the response is that from a layer of GO particles cast onto an electrode surface from which it is impossible to deconvolute effects due to the heterogeneity of the sample and the uncertainty of the inter particle contact resistance. Moreover it is impossible to assess whether all the particles are active or indeed if individual particles show uniform activity across their surface.

Herein, single nanoparticle measurements ${ }^{[4]}$ are used to study both the hydrogen oxidation reaction (HOR) and the hydrogen evolution reaction (HER) on individually impacting graphene oxide particles decorated with palladium nanoparticles (Pd/GOs):

$$
H_{2}-2 e^{-} \underset{H E R}{\stackrel{H O R}{\rightleftarrows}} 2 H^{+}
$$

In this way the issue of the extent of electrical contact is clarified and the intrinsic catalytic activity of individual particles is assessed.

The $\mathrm{Pd} / \mathrm{GO}$ platelets were prepared via a procedure similar

[a] R. Miao, L. Chen, Prof. Dr. R.G.Compton

Department of Chemistry

Physical \& Theoretical Chemistry Laboratory

Oxford University, Oxford, OX1 3QZ (United Kingdom)

Fax: (+ 44) 1865-275-410

E-mail:richard.compton@chem.ox.ac.uk

[b] Prof. Dr. L. Shao

Shanghai Key Laboratory of Materials Protection and Advanced Materials in Electric Power, Shanghai University of Electric Power, 2103 Pingliang Road, Shanghai 200090 (P.R.China)

[c] Prof. Dr. B. Zhang

Shenyang National Laboratory for Materials Science, Institute of Metal Research, Chinese Academy of Sciences, 72 Wenhua Road, Shenyang 110016 (P.R.China)

Supporting information for this article is given via a link at the end of the document.

to a previous study ${ }^{[5]}$ given in the experimental section (details in SI

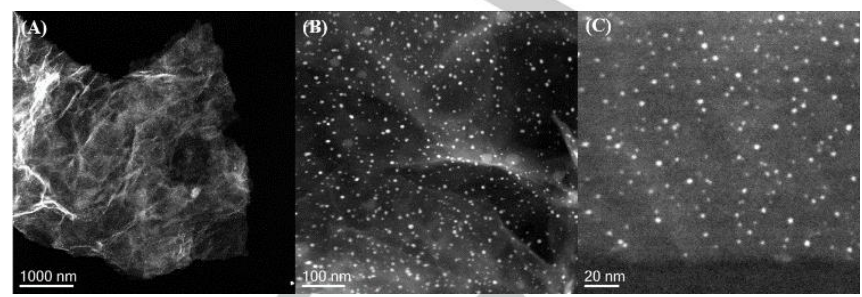

Figure 1. TEM images of graphene oxide nanosheets coated with palladium nanoparticles (Pd/GOs)

Section 2) and characterized by transmission electron microscopy (TEM). As illustrated in Figure 1, a flat sheet-like morphology of $\mathrm{Pd} / \mathrm{GO}$ was observed and quasi-spherical $\mathrm{Pd}$ nanoparticles with the average diameter of $2.7 \pm 0.2 \mathrm{~nm}$ (98 samples) were seen to be highly dispersed on the surface of the GO sheet. The sheets are very approximately square-shaped with a mean side length of $3.1 \pm 0.2 \mu \mathrm{m}$ (34 samples). The corresponding size distribution of the $\mathrm{Pd} / \mathrm{GO}$ sheets and decorated Pd nanoparticles are shown in Figure S1. Note that the thickness of the GO platelets prepared this way is ca. $3.0 \mathrm{~nm}$

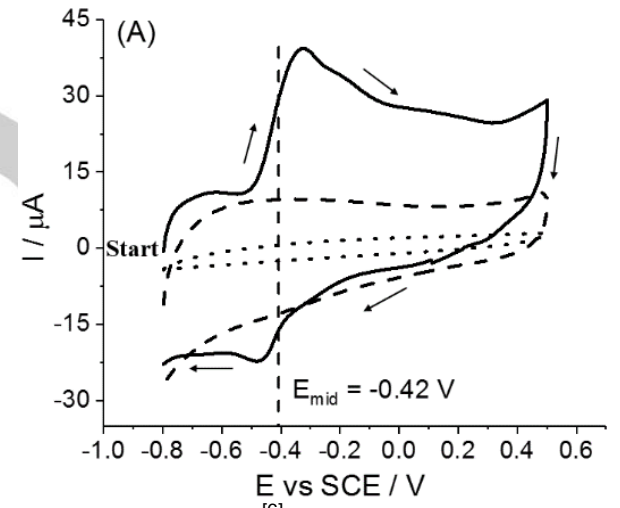

corresponding to $2 \sim 5$ layers. ${ }^{[6]}$

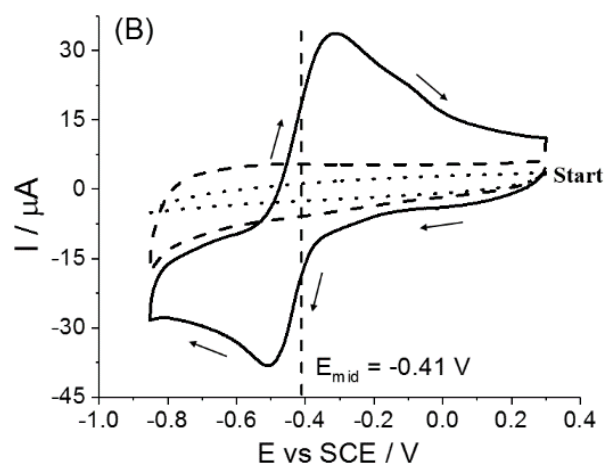

Figure 2. (A) Voltammogram at a bare $\mathrm{GC}$ electrode in $\mathrm{H}_{2}$-saturated $0.2 \mathrm{M}$ $\mathrm{KNO}_{3}$ solution (dotted line), Voltammograms at a Pd/GO-modified GC electrode in $0.2 \mathrm{M} \mathrm{KNO}_{3}$ solution saturated with $\mathrm{N}_{2}$ (dashed line) and $\mathrm{H}_{2}$ (solid line); (B) Voltammogram at a bare $\mathrm{GC}$ electrode in $\mathrm{N}_{2}$-saturated solution containing $0.2 \mathrm{M} \mathrm{KNO}_{3}$ and $1 \mathrm{mM} \mathrm{HNO}_{3}$ (dotted line), Voltammograms at a $\mathrm{Pd} / \mathrm{GO}$-modified GC electrode in $\mathrm{N}_{2}$-saturated $0.2 \mathrm{M} \mathrm{KNO}_{3}$ solution with (solid line) and without (dashed line) $\mathrm{HNO}_{3}$. Scan rate is $50 \mathrm{mV} \mathrm{s}^{-1}$. Vertical dashed line represents the mid-point potential $\left(E_{\text {mid }}\right)$. The start and direction of the voltammogram scans are indicated. 
Both the hydrogen oxidation reaction (HOR) and hydrogen evolution reaction (HER) at the $\mathrm{Pd} / \mathrm{GO}$ were investigated in this study. First, $14 \mu \mathrm{L}$ of $\mathrm{Pd} / \mathrm{GO}$ suspension was drop-casted on a glassy carbon (GC) macroelectrode and ca. four layers of $\mathrm{Pd} / \mathrm{GO}$ nanosheets were immobilized on the electrode surface after drying. The cyclic voltammetry (CV) was then recorded on the $\mathrm{Pd} / \mathrm{GO}$ modified electrode as shown in Figure $2 \mathrm{~A}$ in the absence (dashed line) and presence (solid line) of hydrogen saturated solution. The latter corresponds to $0.77 \mathrm{mM}$ based on Henry's Law solubility. ${ }^{[7]}$ The voltammogram shows a quasireversible oxidation peak at $-0.33 \mathrm{~V}$ vs SCE for hydrogen oxidation at the $\mathrm{Pd} / \mathrm{GO}$ modified electrode. The experimental mid-point potential $\left(E_{\text {mid }}\right)$ of the oxidation reaction is determined as $-0.42 \mathrm{~V}$ vs SCE, in excellent agreement with the thermodynamically calculated value of $-0.43 \mathrm{~V}$ for HOR (see SI Section 4). The oxidative peak current was then studied as a function of scan rate as shown in Figure S2. The peak current was directly proportional to the square root of scan rate, suggesting a diffusion-controlled process. The diffusion coefficient of hydrogen was calculated to be $5.3 \pm 0.4 \times 10^{-9} \mathrm{~m}^{2}$ $\mathrm{s}^{-1}$ via the Randles-Sevcik equation (details in SI Section 5), in agreement with the reported values of $5.0 \times 10^{-9} \mathrm{~m}^{2} \mathrm{~s}^{-1}$ on Platinum microelectrode. ${ }^{[8]} \mathrm{A}$ control experiment was conducted with a bare GC electrode in a hydrogen-saturated solution (dotted line) and no voltammetric features were observed.

Analogous experiments were conducted for HER in the $\mathrm{N}_{2}$ degassed solution with $1 \mathrm{mM} \mathrm{HNO}_{3}$ supported with $0.2 \mathrm{M} \mathrm{KNO}_{3}$, as shown in Figure $2 \mathrm{~B}$. A clear reduction peak at $-0.51 \mathrm{~V}$ vs SCE was seen in the voltammogram recorded with the modified electrode in the presence of $\mathrm{HNO}_{3}$. The $\mathrm{E}_{\text {mid }}(-0.41 \mathrm{~V})$ of the reduction reaction agrees with the thermodynamically calculated value of $-0.44 \mathrm{~V}$ vs SCE and the measured diffusion coefficient of proton is $7.8 \pm 0.3 \times 10^{-9} \mathrm{~m}^{2} \mathrm{~s}^{-1}$, consistent with the literature value of $8.1 \times 10^{-9} \mathrm{~m}^{2} \mathrm{~s}^{-1}{ }^{[8]}$

Having evidenced the catalytic ability of the $\mathrm{Pd} / \mathrm{GO}$ towards both HOR and HER, impact electrochemistry was then conducted to investigate this catalysis on individual $\mathrm{Pd} / \mathrm{GO}$
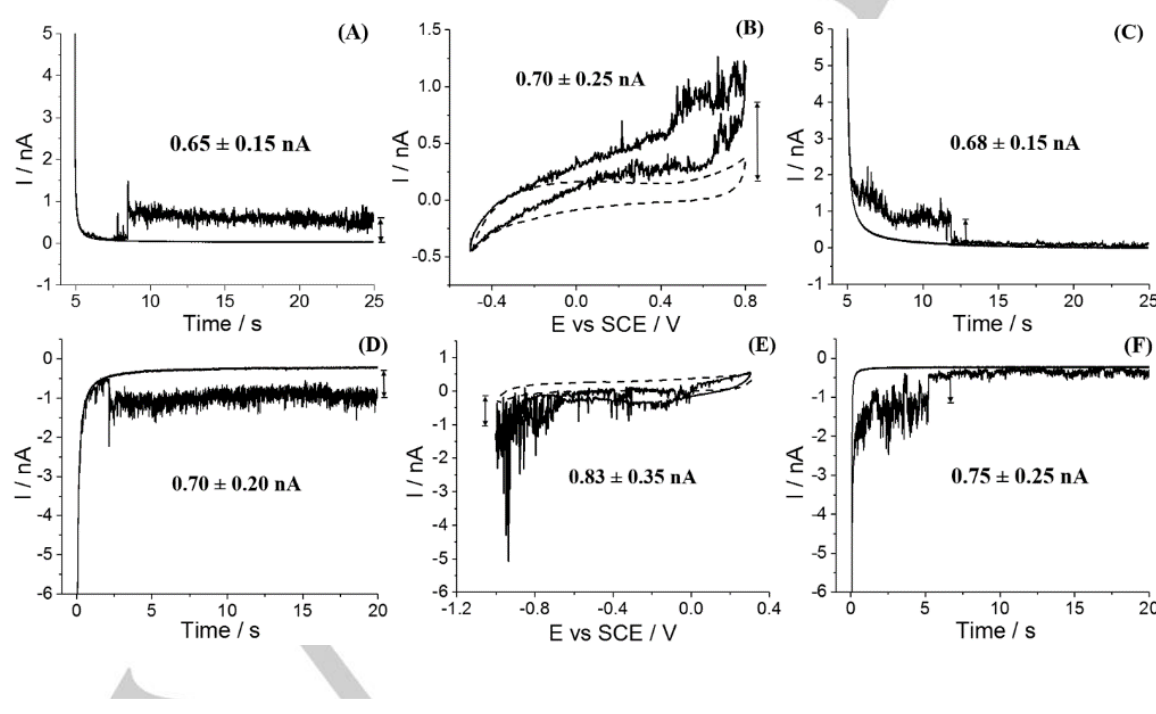

Figure 3. Chronoamperogram showing catalytic oxidative Faradaic steps from $\mathrm{Pd} / \mathrm{GO}$ single particle impacts in $\mathrm{H}_{2}$-saturated $0.2 \mathrm{M} \mathrm{KNO}_{3}$ solution at $0.6 \mathrm{~V}$ (A: collision of $\mathrm{Pd} / \mathrm{GO}$ with the wire electrode; $\mathrm{C}$ : falling-off). Voltammogram (B) of $\mathrm{HOR}$ at single immobilized $\mathrm{Pd} / \mathrm{GO}$ on the wire electrode. $\mathrm{D}, \mathrm{E}$ and $\mathrm{F}$ show the catalytic $\mathrm{HER}$ at $\mathrm{Pd} / \mathrm{GO}$ in presence of $1 \mathrm{mM} \mathrm{HNO}_{3}$.
(F)

particles. A clean carbon fibre microwire electrode (length $c a$. 1 $\mathrm{mm}$ and diameter ca. $7 \mu \mathrm{m}$ ) was inserted into a $\mathrm{H}_{2}$-saturated solution containing $7.1 \times 10^{-15} \mathrm{M} \mathrm{Pd} / \mathrm{GO}$ and $0.2 \mathrm{M} \mathrm{KNO}_{3}$ and chronoamperograms were immediately recorded at $0.6 \mathrm{~V}$ vs SCE. After several chronoamperometric scans, a clear current step was recorded as shown in Figure $3 \mathrm{~A}$ whilst only capacitive charging of the electrode was observed in the absence of $\mathrm{Pd} / \mathrm{GO}$ (Figure S4). This current step was ascribed to the HOR catalysed by a single $\mathrm{Pd} / \mathrm{GO}$ stochastically impacting on the electrode surface. The sharp current onset manifests the arrival of the single entity at the electrode surface, and long duration of the current step reflects that the $\mathrm{Pd} / \mathrm{GO}$ can remain immobilized for ca. $150 \pm 60 \mathrm{~s}$, the long timescale of which is partly indicative of the hindered diffusion of a particle close to a surface. ${ }^{[9]}$ This long residence time of $\mathrm{Pd} / \mathrm{GO}$ at the electrode surface enables the recording of $\mathrm{CV}$ signals for the HOR at single $\mathrm{Pd} / \mathrm{GO}$ entities. Once the arrival of one particle is detected via the current change in the chronoamperogram, a cyclic voltammogram is then immediately performed and completed before the particle departs from the electrode surface. As shown in Figure 3B, the voltammetric response was recorded exhibiting a steady state current at high overpotential for hydrogen oxidation, of which the magnitude $(0.70 \pm 0.25 \mathrm{nA})$ coincides well with that of the Faradaic current $(0.65 \pm 0.15 \mathrm{nA})$ detected via chronoamperometry. The observed current fluctuations likely correlate with the nanoscopic motion of the particle at the electrode surface that modulates the electric connection between the electrode and particle. Note the forward and reverse scans of the cyclic voltammetry show relatively little hysteresis consistent with the convergent/divergent diffusion of the nano entity. Figure $3 \mathrm{C}$ shows a step-off of the current in the chronoamperometric profile, indicating the loss of immobilized of $\mathrm{Pd} / \mathrm{GO}$ from the electrode surface.

Impacts of $\mathrm{HOR}$ at single $\mathrm{Pd} / \mathrm{GO}$ were then recorded at a series of applied potentials from $-0.4 \mathrm{~V}$ to $0.8 \mathrm{~V}$ and the average current steps at each potential were obtained, as shown in Figure $4 \mathrm{~A}$, where the average current steps at potentials more (C) positive than $0.6 \mathrm{~V}$ shows a plateau at $\mathrm{ca}$. $0.60 \mathrm{nA}$. Mass-transport corrected Tafel analysis $^{[10]}$ was then performed on the 'voltammogram-like' feature in Figure 4A to separate out the electron transfer kinetics from the diffusion and give a single-particle measurement of the apparent anodic transfer coefficient $\beta$ for the HOR (details in SI Section 7). The apparent $\beta$ was estimated to be $0.28 \pm$ 0.01 in accord with that obtained from the macroelectrode (0.30). 
Analogous impact experiments were conducted for HER in the $\mathrm{N}_{2}$-degassed solution with $1 \mathrm{mM} \mathrm{HNO}_{3}$ supported with $0.2 \mathrm{M}$
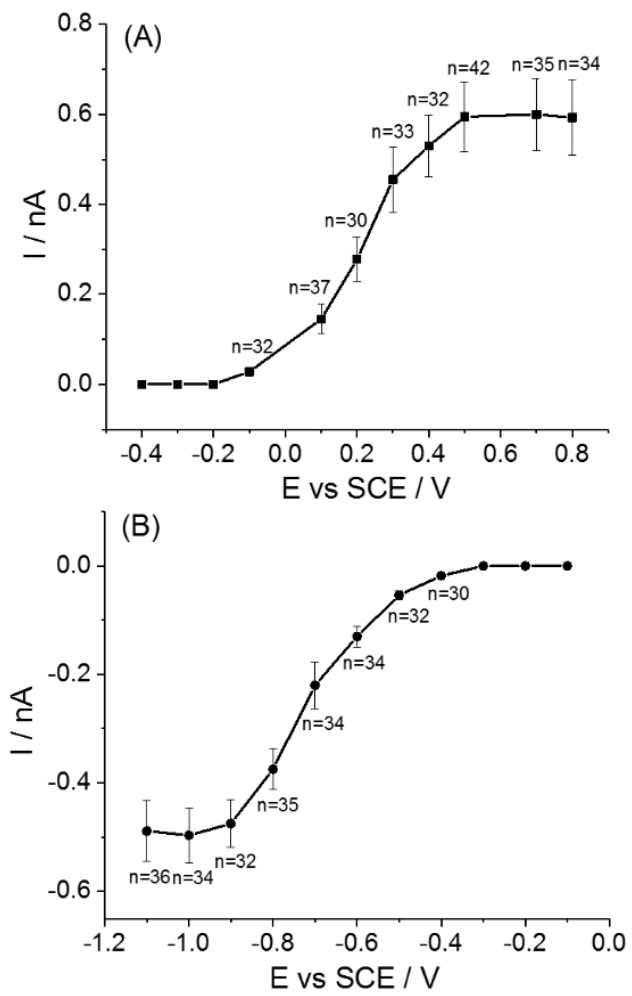

$\mathrm{KNO}_{3}$ on a carbon microwire electrode, as shown in Figure 3D-F. Potential variation study was also conducted and the average current steps plateaued at around $-0.49 \mathrm{nA}$ at potentials more

Figure 4. The average Faradaic step currents for HOR (A) and HER (B) on collided individual $\mathrm{Pd} / \mathrm{GO}$ at different potentials. The error bars are derived from $S D /(n)^{1 / 2}$, where $S D$ is the standard deviation and $n$ is the number of the steps analysed.

negative than $-0.9 \mathrm{~V}$ vs. SCE, as shown in Figure $4 \mathrm{~B}$. The apparent cathodic transfer coefficient $\alpha$ was found to be $0.26 \pm$ 0.01 (vs. 0.32 for dropcasted macroelectrode).

Under diffusion-controlled conditions, the reaction rates of both HOR and HER are not sensitive to the Pd coverage on the $\mathrm{GO}$ nanosheets because the interparticle distance of Pd on GO is tiny compared to the diffusion layer thickness established. Consequently, both the chronoamperometric current steps and

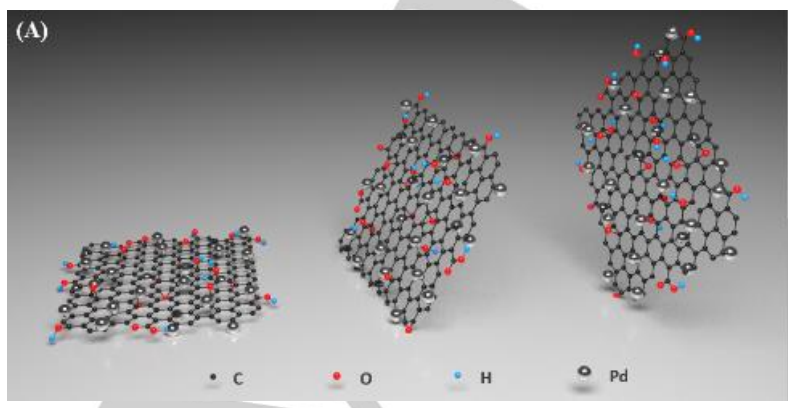

the quasi-steady-state current from $\mathrm{CV}$ of the impacted $\mathrm{Pd} / \mathrm{GO}$ allow in principle the assessment of the sizing of the decorated $\mathrm{GO}$ platelets. First, the $\mathrm{Pd} / \mathrm{GO}$ platelets immobilized flat on the surface of the carbon fibre as Scheme $1 \mathrm{~A}$ shows was modelled as a square electrode, considering the catalysis can proceed on the whole GO plane. The side length was calculated to be ca. $0.36 \mu \mathrm{m}$ and $0.31 \mu \mathrm{m}$ from HOR and HER respectively (details in SI Section 8). However, these two values are much smaller than the actual size obtained from TEM, which implies that the contact between the $\mathrm{GO}$ and electrode is likely partial. If the contact with the platelet edge or corner (Scheme 1A) were considered, the $\mathrm{Pd} / \mathrm{GO}$ was treated as a microband electrode using the known width of $3.0 \mathrm{~nm}$. The length of the platelets was determined as $3.3 \pm 0.1 \mu \mathrm{m}$ and $2.9 \pm 0.1 \mu \mathrm{m}$ from the HOR and HER limiting currents respectively (details in SI Section 8). This is consistent with the value from TEM analysis for the dimension of the square platelets. This was further evidenced by comparing the size distributions of these electrochemically assessed lengths with the data obtained from TEM, as shown in Figure S6. The correspondence between TEM and electrochemical sizing

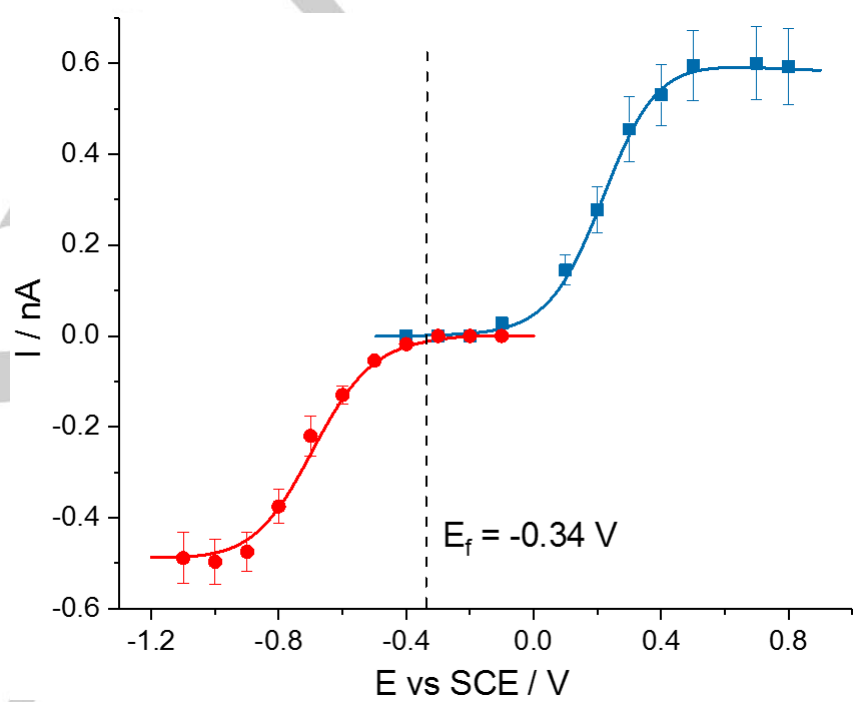

allows us to suggest that both HOR and HER only occur at or near the contact area between $\mathrm{Pd} / \mathrm{GO}$ and electrode surface, which results from, at least in part, the high resistance of the ultrathin GO blocks preventing movement of electrons through the whole sheet.

To explore the kinetics of both reactions, DIGISIM was next employed to model the observed voltammetry based on ButlerVolmer kinetics. A hemicylindrical band electrode geometry with the equivalent radius $r$ of $1.0 \mathrm{~nm}$ according to the equation $r=w$ I $\pi$ was used to approximate a microband electrode with a side length $w$ of $3.2 \mu \mathrm{m}$ (Scheme 1B). ${ }^{[11]}$ The formal potential of reactions, transfer coefficients and diffusion coefficients of both hydrogen and proton are given above. Consequently, the rate constant $k$, the only unknown parameter, can be determined by fitting the numerical simulations to the voltammograms from impact electrochemistry (details in SI Section 10). Figure 5 shows the excellent fitting between simulated voltammograms and the experimental data obtained from individual $\mathrm{Pd} / \mathrm{GO}$, and very fast
Scheme 1. (A) Models of $P d / G O$ particles impacting onto the surface of carbon fib and corner (right). (B) The highlighted red rectangle schematically represents the li the contact between $\mathrm{Pd} / \mathrm{GO}$ particles and electrode.
Figure 5. DIGISIM-simulated curves for HOR (blue line) and HER (red line) based on experimentally voltammogram-like features (squares for HOR and circles for HER). 
rate constants, $\mathrm{k}_{\mathrm{HOR}}=0.1 \mathrm{~cm} \mathrm{~s}^{-1}$ and $\mathrm{k}_{\mathrm{HER}}=1.6 \mathrm{~cm} \mathrm{~s}^{-1}$, were obtained. The voltammetric visibility of fast reaction rates is attributed to the very high mass transport conditions for HOR and HER occurring on single Pd/GO.

To conclude, both hydrogen oxidation reaction and hydrogen evolution reaction on ensemble and individual $\mathrm{Pd} / \mathrm{GO}$ were investigated in this work. Impact electrochemistry reveals that the reactions only take place near the contact area, formally modelled as analogous to a microband electrode, between the $\mathrm{GO}$ and the electrode, as a result of the high resistance of the ultrathin GO with the size of the active area possibly controlled by tunnelling from the substrate electrode. Moreover, important and meaningful kinetic data was extracted via simulation showing fast electrochemical rate constants of $k_{\mathrm{HOR}}\left(0.1 \mathrm{~cm} \mathrm{~s}^{-1}\right)$ and $\mathrm{k}_{\mathrm{HER}}\left(1.6 \mathrm{~cm} \mathrm{~s}^{-1}\right)$ at high mass transport conditions. This provides a new generic approach for the accurate assessment of the kinetics for the catalytic reactions.

\section{Conflicts of interest}

The authors declare no conflicts of interest. a) C. K. Chua, M. Pumera, Chem Soc Rev 2014, 43, 291312; b) Z. Sofer, J. Luxa, O. Jankovsky, D. Sedmidubsky, T. Bystron, M. Pumera, Angew Chem Int Edit 2016, 55, 11965 $11969 ;$ c) A. Bagri, C. Mattevi, M. Acik, Y. J. Chabal, M. Chhowalla, V. B. Shenoy, Nat Chem 2010, 2, 581-587.

[2] A. Y. S. Eng, H. L. Poh, J. Luxa, Z. Sofer, M. Pumera, Rsc Adv 2013, 3, 10900-10908.

[3] C. Punckt, M. A. Pope, Y. F. M. Liu, I. A. Aksay, J Electrochem Soc 2016, 163, H491-H498.

[4] a) W. Xu, G. Zou, H. Hou, X. Ji, Small 2019, e1804908; b) L. K. Allerston, N. V. Rees, Curr Opin Electroche 2018, 10, 31-36; c) K. J. Stevenson, K. Tschulik, Curr Opin Electroche 2017, 6, 38-45; d) G. Zampardi, C. BatchelorMcAuley, E. Katelhon, R. G. Compton, Angew Chem Int Edit 2017, 56, 641-644; e) W. Xu, Y. G. Zhou, X. B. Ji, J Phys Chem Lett 2018, 9, 4976-4980.

[5] a) L. D. Shao, X. Huang, D. Teschner, W. Zhang, Acs Catal 2014, 4, 2369-2373; b) W. S. Hummers, R. E. Offeman, $J$ Am Chem Soc 1958, 80, 1339-1339.

[6] a) K. P. Loh, Q. L. Bao, G. Eda, M. Chhowalla, Nat Chem 2010, 2, 1015-1024; b) G. Eda, M. Chhowalla, Adv Mater 2010, 22, 2392-2415; c) S. Stankovich, R. D. Piner, S. T. Nguyen, R. S. Ruoff, Carbon 2006, 44, 3342-3347.

E. Wilhelm, R. Battino, R. J. Wilcock, Chem Rev 1977, 77, 219-262.

[8] X. Jiao, C. Batchelor-McAuley, E. Katelhon, J. Ellison, K. Tschulik, R. G. Compton, J Phys Chem C 2015, 119, 94029410.

[9] S. Eloul, R. G. Compton, J Phys Chem Lett 2016, 7, 43174321.

Keywords: Graphene Oxide - Electron Transfer • Heterogeneous Catalysis - Single Particle Electrochemistry • Palladium Nanoparticles
R. G. Compton, C. E. Banks, Understanding voltammetry, Third edition. ed., World Scientific, London, 2018

[11] J. Heinze, Angew Chem Int Edit 1993, 32, 1268-1288. 


\section{COMMUNICATION}

The active area for catalysis on the HOR and the HER is at/near the contact part between graphene oxides and electrode surface.

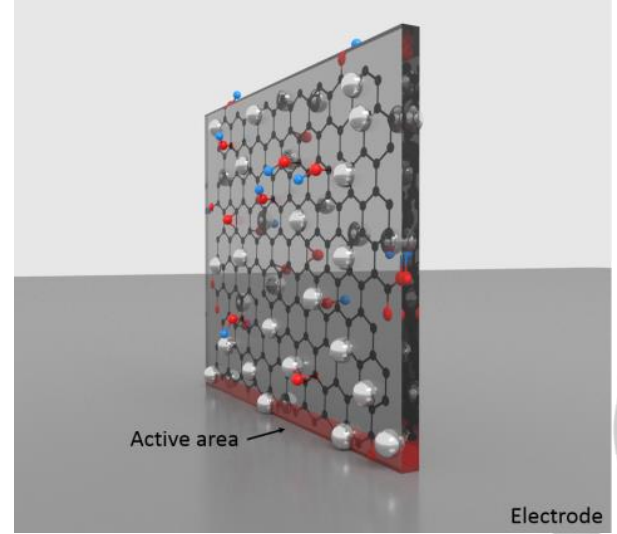

Ruiyang Miao, Lifu Chen, Lidong Shao, Bingsen Zhang and Richard G. Compton*

Electron Transfer to Decorated Graphene Oxide Particles 